\title{
An Empirical Study on College Students'"Campus Network Loan" from the Perspective of Internet Finance
}

\author{
Haoyuan Weng, Yuxia Zhang * \\ Quanzhou Normal University \\ Fujian, China \\ zyx11603@163.com
}

\author{
Xiaofang Wang \\ Liming Vocational University archives \\ Quanzhou, China
}

\begin{abstract}
Campus network loan has become a hot issue around college students. The negative news caused by "campus network loan" has emerged in an endless stream. A small number of students have been accused of high debts and even suicides. The Internet campus finance has attracted great attention from all walks of life. Questionnaires and field interviews, starting from the current situation of college students' "campus network loan" in Fujian Province, dialysis of the social harms that may be caused by the family education, school guidance, government supervision, and self-discipline of online lending platform.
\end{abstract}

Keywords-College student; Campus network loan; Empirical research

\section{INTRODUCTION}

\section{A. The Aim and Meaning of the Research}

In recent years, while Internet finance has extended on university campuses, campus lending has become a hot spot of concern to all sectors of society. Many college students are trapped in illegal campus online loans due to lack of correct understanding, and college students are unable to repay huge loans and cause suicide tragedies. The tragedy was exposed by the media one by one. The " campus network loan" was gradually labeled as "campus harm" [1], which brought extremely serious adverse effects to the victims' families, schools and society. The investigation of the status of loans is an urgent task.

\section{B. Research Content and Research Methods}

This study selects college students in Fujian Province as an example to investigate the current situation of campus online loan for college students. Using questionnaires and individual interviews, this paper conducts empirical research on college students' online loan, in order to provide research for college campus network loan in Fujian Province. The real research foundation and research direction.

\section{INVESTIGATION BASED ON " CAMPUS NETWORK LOAN" OF COLLEGE STUDENTS IN FUJIAN PROVINCE}

In order to understand the use of online lending in colleges and universities, this research topic is based on the students of colleges and universities in Fujian Province, using questionnaires and field interviews.A total of 505

Foundation Project:

1.Quanzhou Normal University 2017 Open Experimental Project (20170159)

2.2018 Fujian Province Young and Middle-aged Teacher Education Research Project "I Offer Good Strategies for Building New Fujian" (United Front Work Project) (Key Funding Project) (JZ180019).

3.Quanzhou Normal University Student Innovation and

Entrepreneurship Training Program Project Funding(201810399120)

*Corresponding author: Yu -Xia Zhang zyx11603@163.com questionnaires were collected from college students' knowledge, acceptance and usage of campus online lending. 465 questionnaires were obtained through screening.

Among the survey students, students using campus network loan accounted for $5.15 \%$ of the total number of surveys. Although the proportion is not large, the Internet campus consumer finance with campus network loan as the main form has penetrated into the university campus and has become a hot spot.

The respondents expressed different views on the nature of campus network loan. You can see from Fig.1.The Cognition of Campus Loan Nature of College Students.Among them, $69.11 \%$ of the students thought that campus network loan were usury loans, $17.65 \%$ of the students thought that the nature of campus network loans was Internet finance, and $13.24 \%$ of the students thought that campus network loan were the same as ordinary loans. $6.62 \%$ of the students think that the interest rate of campus network loan is low, $46.32 \%$ of the students think that the interest rate of campus network loan is high, which easily leads to insufficient repayment ability. The rest of the respondents do not understand the loan interest rate of campus network loan.

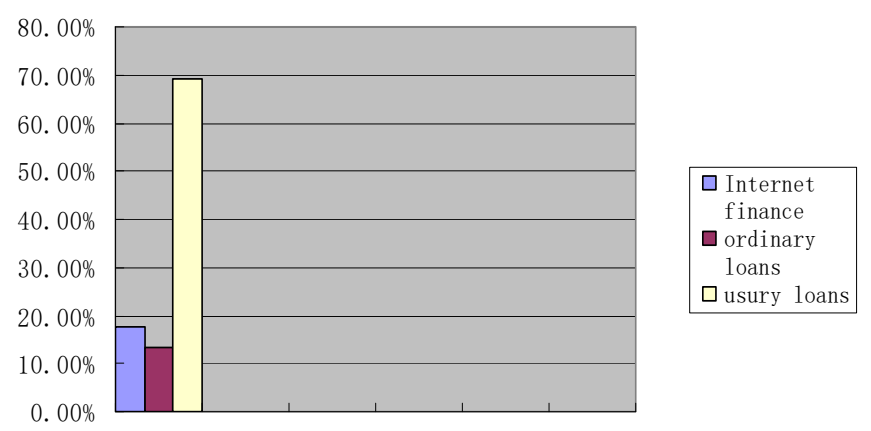

Fig. 1. The Cognition of Campus Loan Nature of College

Survey summary: Most college students have a general family and weak spending power; college students have low risk awareness and poor risk prevention awareness; the 
campus network lending market has uneven development levels. In individual interviews, most students believe that "Campus network loan" will lead to a comparison between students and show off their wealth, which is not conducive to personal long-term physical and mental development and personality shaping. In general, the adverse effects of campus network loan still occupy a dominant position in the minds of college students.

\section{THE CAUSE OF "CAMPUS NETWORK LOAN" BECAME THE CAUSE OF "CAMPUS HARM"}

\section{A. The Conflict Between College Students' Consumption Ability and Irrational Consumption Demand}

The monthly expenditure of college students is basically distributed within 1000-2000 yuan. From the source of living expenses, $91.18 \%$ of the respondents' living expenses are from parents. In the monthly expenses, the proportion of eating and shopping is relatively heavy. Accounted for $66.18 \%, 30.15 \%$.

Entering the new environment of the university, college students have different differences in family background and wealth. The comparison and vanity mentality have begun to spread in the bottom of their hearts. $92.21 \%$ of the respondents believe that the reason why campus network loan are aimed at college students is that college students have more consumer demand and desire for money. Almost all of the daily life expenses of college students are provided by parents. For students, it is more difficult to implement bank loans, while campus network loan are convenient, no need to provide guarantees or provide less guarantees, and the loan amount is large. The program is also relatively loose and so on.

\section{B. Insufficient Awareness of College Students' Financial Risks}

Many college students lack social experience, and financial risk prevention awareness, credit risk awareness, self-protection awareness and legal awareness are indifferent. According to the survey statistics, $46.1 \%$ of students do not understand the campus network lending rate, and it is easy to ignore other loans and other interest. Conditions, it is more difficult to identify the opaque rules of the online lending platform. Without knowing the specific information of the lending platform, the relevant lending contracts are signed, there is no legal evasion of legal risks, and it is easy to fall into the trap of illegal online lending. [2]

\section{Disorderly Expansion of the Online Lending Platform}

Today's online lending platforms generally lack a strict management system and loan review system. The low registration threshold is an important reason for the increasingly chaotic management of online lending platforms. Individual institutions have even lost their professional ethics and moral bottom line, evolving campus online loans into actual usury loans, and using illegal means such as releasing nude photos and threatening intimidation to attract debts, resulting in many students not being able to bear mental pressure and choose to commit suicide.

\section{Insufficient Credit Safety Education}

The frenzy and incitement of campus network loan in the group of college students also reflects the shortcomings of some colleges in the process of education and guidance of students. The understanding of the basic situation of college students' study and life is not comprehensive and detailed. The credit construction and legal popularization of colleges and universities are not paid enough attention, and there is no relevant moral education.

\section{E. Government Departments are Negligent}

The regulatory measures of the relevant government departments are still relatively old. Today, when the campus loan is developing rapidly, it is obviously not applicable. The relevant policies are not well-developed, and it is easy for the illegal online lending platform to drill legal and regulatory loopholes. This is tantamount to burying a time bomb in people's lives, and the occurrence of the campus network loan tragedy also indicates the moment of the bomb explosion.

\section{CONSTRUCTING A “CAMPUS NETWORK LOAN" RISK PREVENTION MECHANISM}

\section{A. Building a Government-led Legal Monitoring Mechanism}

Strengthen the qualification review and risk supervision of the campus online loan platform, improve the access conditions of the online loan platform, and place the "campus network loan" related enterprises and platforms under the strict financial risk supervision of the government; Improve the supervision system, standardize the supervision system, and severely crack down on illegal and illegal behaviors of campus online loans. At the same time, we encourage the development of high-quality platforms, ensure the orderly development of the financial loan market order and the vital interests of college students; improve the student loan system, simplify the loan procedures, and open the green channel for students with financial difficulties or active entrepreneurship. Provide support and convenience.

\section{B. Constructing the Educational Value Guidance Mechanism Based on University Positions}

In education management, the university strengthens the integrity education, cultivates the contract spirit of the students, guides the students to establish a correct consumption concept, instills the content of the responsible consumption theory, and instructs students by organizing special lectures, holding financial knowledge contests, and conducting theme group day activities. Uncover the true face of illegal campus network loan, strengthen college students' cybersecurity education, and provide students with specific emergency measures and remedies for emergencies such as fraud and coercion, improve their risk prevention awareness; set up financial planning courses to train students The "financial business" guides students to recognize themselves, face themselves, plan their own self and use their own funds, and enhance their ability to identify and prevent campus network loan traps. [3] 


\section{Create a Network Loan Environment Based on the Online Loan Platform}

The online lending platform itself should standardize the management system and set a scientific and strict lending rate based on the bank interest rate. Strict loan review procedures, severe penalties for bad behavior; establish industry selfdiscipline mechanisms to improve industry self-discipline awareness, companies must always put integrity management in the first place, to eliminate all concealed and fraudulent publicity and marketing activities. To cultivate future customers and guide students to rational consumption as the business purpose of the company. [4]

\section{Simple Lifestyle Guide with Family Education as a Supplement}

Parents should be good examples of children, lead by example, rationally look at material money, help children establish a correct and healthy view of consumption through the subtle influences in daily life; pay attention to the flow of children's expenditures, strengthen the supervision of children's consumption, when children appear in the crowd, compare When you are mentally, you should guide your child's consumption concept in a timely manner, cultivate your child's financial management habits, rationally plan daily expenses, optimize the consumption structure, and improve your child's self-control ability and management ability.

In short, campus lending is a double-edged sword. In order to ensure the sustainable and healthy development of “ campus network loan", the government, universities, families and enterprises must work together to fulfill their respective duties and develop the Internet campus in an orderly manner. On the basis of the consumer finance market, standardize the order of the campus lending financial market, popularize the financial knowledge education of college students, unite the powers of universities, families and banking supervisors, network supervisors, public security and other departments to establish a linkage management mechanism and strengthen joint supervision. Only the government, enterprises, and universities can truly perform their duties, strengthen supervision and reasonable guidance, and ensure the healthy and orderly development of the online loan market,campus network loan can return to their essence and become a tool that is beneficial to college students and plays a positive role in economic development.

\section{REFERENCE}

[1] H.Q. Wu and X.Y. Cheng, "The generation and response of the problem of "campus network loan " under the perspective of risk society," Contemporary Youth Research, vol. 2018(01), pp. 1-2.

[2] K. Wang, "The Status and Countermeasures of campus network loan problem in China_Based on Empirical Analysis of Shanghai and Henan," Juvenile Delinquency, vol. 2017(6), pp. 42-43.

[3] C.X. Huang, X.Y. Meng, and H.C. Li, "The lack of college students' credit safety education and the coping strategies highlighted by "campus network loan "," Senior School Assistant Director, vol. 2017(06), pp 73-75.

[4] Q. Xu, "Exploring the Risk Prevention and Education Guidance Mechanism of "campus network loan"," Xuegong Window, vol. 2017(08), pp. 63-64. 